\title{
Effects of a Novel Dihydropyridine Derivative Calcium Channel Blocker, NKY-722, on Regional Hemodynamics, and Its Influences on the Effects of Endothelin in Anesthetized Rats
}

\author{
Hakuo Takahashi ${ }^{\#}$, Shohei Nakamura*, Hiroaki Shirahase*, \\ Masato Nishimura, Tadashi Nakanishi, and Manabu Yoshimura
}

\begin{abstract}
Regional vascular responses to NKY-722 (NKY), a novel dihydropyridine derivative calcium channel blocker, and the effects on the responses to endothelin (ET) were investigated using tracer microspheres with a reference sample method in anesthetized rats. Intravenous injections of $\mathrm{NKY}, 0.2 \mathrm{and} 2 \mathrm{mg} / \mathrm{kg}$, decreased blood pressure and total peripheral resistance dose-dependently. Cardiac index significantly increased only with the high dose regardless of bradycardia. Regional blood flow significantly changed with NKY: It increased in the brain, brown adipose tissue (BAT), intestine, colon and skin, but decreased in the liver, spleen, kidneys, adrenals and skeletal muscle. NKY decreased the regional vascular resistance in the brain, heart, lungs, BAT, intestine, colon and skin, but increased it in the liver, spleen and skeletal muscle. ET significantly increased blood pressure, but this was abolished by pretreatment with the low and high doses of NKY. Cardiac index became significantly lower with ET, and was not affected by NKY. Total peripheral resistance after ET remained lower with NKY pretreatments. ET decreased the blood flow mainly in the liver, spleen, kidneys, adrenals, BAT, intestine, colon, and skeletal muscle. Pretreatments with NKY prevented the decrease of flow caused by ET in the kidneys, adrenals, BAT, intestine, colon and skeletal muscle. These findings indicate that NKY lowers blood pressure mainly by decreasing the peripheral vascular resistance, and that NKY blunts many, but not all, endothelin effects on vasculature. (Hypertens Res 1994; 17: 29-34)
\end{abstract}

Key Words: calcium channel blocker, endothelin, regional blood flow, brown adipose tissue, rat

Since the effects of dihydropyridine calcium channel blockers are relatively vasoselective as compared to verapamil and diltiazem, they have been widely used for the treatment of hypertension. NKY-722 is a novel, water-soluble (hydrophilic), 1,4-dihydropyridine derivative, which has been shown to exert long-lasting vasodepression in spontaneously hypertensive rats (1). Since it inhibits calcium-induced contractions of isolated dog mesenteric arteries, calcium antagonism has been suggested for its mechanism of action (1). The effect of NKY is essentially identical to that of currently available, lipophilic 1,4-dihydropyridine calcium channel blockers (2). Because it can be easily dissolved in water and causes prolonged vasodepression, NKY is suitable not only for clinical use but also for basic scientific research.

Endothelin (ET) is a potent vasoconstrictor peptide first found in the culture medium of aortic endothelial cells (3). With intra-venous or -arterial in- jection, its potent vasoconstrictive activity affects vascular smooth muscle cells in diverse organs and tissues including the coronary, cerebral, renal and hind-limb arteries, resulting in a sustained rise in systemic arterial pressure for more than $1 \mathrm{~h}$. The vasoconstriction has been shown to be blocked by the calcium channel blocker, nicardipine (4). Although influences of ET on systemic arterial pressure and regional blood flow have been documented in some kinds of animals $(5,6)$, less is known about the interaction of ET and calcium channel blockers on regional blood flow.

The present study was undertaken to compare the regional vascular effects of the calcium channel blocker, NKY, and ET, and then to assess the hemodynamic interactions of these agents.

\section{Materials and Methods}

Male Wistar rats at $10-12$ weeks of age $(278 \pm 3 \mathrm{~g})$

From the Department of Clinical Laboratory and Medicine, Kyoto Prefectural University of Medicine, Kamikyo-ku, Kyoto, ${ }^{*}$ Research Laboratories, Kyoto Pharmaceutical Industries, Ltd., Nakakyo-ku, Kyoto Japan, \# Present address: Department of Clinical Sciences and Laboratory Medicine, Kansai Medical University, Moriguchi, Osaka, Japan.

Address for Reprints: Hakuo Takahashi M.D., Prof., Department of Clinical Sciences and Laboratory Medicine, Kansai Medical University, Fumizono-cho-1, Moriguchi City, Osaka 570, Japan.

Received March 11, 1993; accepted in revised form September 21, 1993. 
were used. All experiments were performed under anesthesia with urethane $(1.1 \mathrm{~g} / \mathrm{kg}$, i.p. $)$. Catheters were inserted into the femoral artery and vein, and into the left cardiac ventricle through the right carotid artery. Blood pressure was recorded continuously during the experiments by connecting the femoral arterial catheter to a small volume displacement transducer (TP-200T, Nihon Kohden, Tokyo). Pulse rate triggered by the arterial pulse wave was calculated automatically with a tachometer (SEN-6104, Nihon Kohden, Tokyo). Blood pressure and heart rate were recorded for more than $10 \mathrm{~min}$ until the stabilization of these parameters. Then, one of the drugs or the vehicle was injected into the femoral vein in a volume of $10 \mu \mathrm{l}$, followed by a $0.15-\mathrm{ml}$ saline flush. Ten min later, radioactive microspheres were injected into the left ventricle and the reference sample was collected from the femoral artery.

\section{Measurements of Regional Blood Flow with Radioactive Microspheres}

Microspheres, $15 \mu \mathrm{m}$ in diameter, labeled with ${ }^{57} \mathrm{Co}$ and suspended in normal saline plus $0.01 \%$ Tween 80 (NEM-022A, New England Nuclear), were used in the present study. Radioactive microspheres in a disposable syringe were measured for radioactivity in a scintillation counter before injections into animals. Approximately 400,000 microspheres labeled with an isotope chosen in a random order were injected into the left ventricle through the carotid catheter at a volume of $0.05 \mathrm{ml}$ in about $3 \mathrm{~s}$ followed by a $0.1-\mathrm{ml}$ saline flush. Starting immediately before the microsphere-injection, a reference blood sample was withdrawn from the femoral arterial catheter for $30 \mathrm{~s}$ continuously $(0.82 \mathrm{ml} / \mathrm{min})$ with a withdrawal pump (Igakushoin Kikai Ltd., Tokyo, Japan). At the end of experimentation, the animals were sacrificed with intravenous injections of concentrated potassium chloride solution, and the organ and tissue samples were blotted and weighed. The used syringe (remaining radioactive microspheres), the reference blood samples, and the organ and tissue samples were each measured for radioactivity in a scintillation counter. Cardiac output $(\mathrm{CO})$, regional blood flow (RBF) and regional vascular resistance (RVR) were calculated using the following equations:

$$
\mathrm{CO}=\frac{\mathrm{TOTA} \times \mathrm{RSR}}{\mathrm{RSA}} \mathrm{RBF}=\frac{\mathrm{TiA} \times \mathrm{CO}}{\mathrm{TOTA}} \mathrm{RVR}=\frac{\mathrm{MAP}}{\mathrm{RBF}}
$$

where RSR is the withdrawal rate $(/ \mathrm{min})$ of the reference sample, RSA the radioactivity, TOTA the total activity of microspheres injected, and TiA the radioactivity in the tissue samples. Total radioactivity was calculated by subtracting the remaining activity in the syringe from the whole activity counted before the injection. Cardiac index (CI) was calculated as $\mathrm{CO}$ divided by the animal weight. $\mathrm{RBF}$ was expressed as blood flow (ml)/g-tissue weight per minute. RVR was calculated as mean arterial pressure (MAP) divided by RBF. Systemic vascular resistance was calculated as MAP divided by $\mathrm{CO}$, and was adjusted for weight.

\section{Drug Injections and Statistics}

NKY-722, a calcium channel blocker (Kyoto Pharmaceutical Industries Ltd., Kyoto, Japan) and endothelin-1 (Peptide Institute, Osaka, Japan) were dissolved into saline. The solution was diluted with saline to adjust the injection volume to be $10 \mu \mathrm{l}$ for each injection.

Data, expressed as averages \pm SEM, from more than three groups of rats were compared by analysis of variances; for $\mathrm{F}$ ratios significant at $5 \%$ or less, differences between pairs of means were examined by Duncan's new multiple range test.

\section{Results}

Effects of NKY on the Hemodynamic Parameters (Table 1): NKY decreased blood pressure immediately after the intravenous (IV) injections of NKY, reaching the peak level between at 5 and 15 min, and the peak level lasted for more than 20 min. The magnitude of vasodepression at the peak was dose-dependent. Heart rate did not change with the low $(0.2 \mathrm{mg} / \mathrm{kg})$ dose, but decreased with the high dose $(2 \mathrm{mg} / \mathrm{kg})$. Arrhythmias were thereby accompanied by bradycardia; although it was not confirmed by an electrocardiogram, atrioventricular

Table 1. Hemodynamic Parameters Measured in 6 Groups of Rats

\begin{tabular}{|c|c|c|c|c|c|c|}
\hline Rat Group & $(n)$ & $\begin{array}{c}\text { MAP } \\
\mathrm{mm} \mathrm{Hg}\end{array}$ & $\begin{array}{c}\text { HR } \\
\text { beats/min }\end{array}$ & $\begin{array}{c}\mathrm{CO} \\
\mathrm{ml} / \mathrm{min}\end{array}$ & $\begin{array}{c}\mathrm{CI} \\
\mathrm{ml} / \mathrm{min} / \mathrm{kg}\end{array}$ & $\begin{array}{c}\text { TVR } \\
\mathrm{mmHg} / \mathrm{ml} / \mathrm{min} / \mathrm{kg}\end{array}$ \\
\hline Control & (10) & $103 \pm 4.3$ & $317 \pm 20.6$ & $61 \pm 4.6$ & $204 \pm 28.3^{\dagger}$ & $0.56 \pm 0.082^{\dagger \dagger}$ \\
\hline NKY-L & $(8)$ & $77 \pm 3.4^{*+\dagger}$ & $327 \pm 14.8^{* \dagger}$ & $65 \pm 4.9^{\dagger}$ & $223 \pm 10.7^{\dagger \dagger}$ & $0.35 \pm 0.019^{\dagger \dagger}$ \\
\hline NKY-H & (8) & $76 \pm 2.3^{*+\dagger}$ & $237 \pm 37.7^{*}$ & $76 \pm 4.3^{* * t \dagger}$ & $267 \pm 12.3^{*+\dagger}$ & $0.29 \pm 0.016^{*+\dagger}$ \\
\hline ET & (7) & $114 \pm 4.7$ & $331 \pm 16.0$ & $48 \pm 5.1$ & $139 \pm 16.4^{*}$ & $0.94 \pm 0.131^{* *}$ \\
\hline NKY-L/ET & (8) & $79 \pm 2.7^{*+\dagger}$ & $330 \pm 15.9$ & $51 \pm 3.1$ & $179 \pm 8.7$ & $0.45 \pm 0.032^{\dagger \dagger}$ \\
\hline NKY-H/ET & $(8)$ & $80 \pm 2.2^{* * \dagger}$ & $208 \pm 40.2^{*+\dagger}$ & $52 \pm 4.2$ & $184 \pm 17.7$ & $0.46 \pm 0.043^{\dagger \dagger}$ \\
\hline$F$ ratio & & 21.06 & 4.74 & 5.29 & 7.30 & 9.68 \\
\hline$p<$ & & 0.0001 & 0.0020 & 0.001 & 0.0001 & 0.0001 \\
\hline
\end{tabular}

Abbreviations: MAP, mean arterial pressure; HR, heart rate; CO, cardiac output; $\mathrm{CI}$, cardiac index; TVR, total vascular resistance; -L, low dose $(0.2 \mathrm{mg} / \mathrm{kg})$; - $\mathrm{H}$, high dose $(2 \mathrm{mg} / \mathrm{kg})$; ET, endothelin-1 $(5 \mu \mathrm{g} / \mathrm{kg}) ;-\mathrm{L} / \mathrm{ET}$, low dose $+\mathrm{ET}$; -H/ $\mathrm{ET}$, high dose $+\mathrm{ET}\left({ }^{*} p<0.05,{ }^{*} p<0.01 v s\right.$. control group, ${ }^{\dagger} p<0.05,{ }^{\dagger \dagger} p<0.01 v s$. ET group with multiple range test $)$. 
block may have occurred. $\mathrm{CO}$ and $\mathrm{CI}$ increased with the high dose. Total peripheral resistance decreased with the high dose.

Effects of NKY on Regional Blood Flow (Table 2): NKY did not affect blood flow in the heart and lungs. It increased the flow in the brain, BAT, intestine, colon and skin, but decreased it in the liver, spleen, kidneys, adrenals and skeletal muscle.

Effects of NKY on the Regional Vascular Resistance (Fig. 1-a, b): NKY decreased the vascular resistance in the brain, heart, BAT, intestine, and colon, but rather tended to increase it in the spleen, and skeletal muscle. Renal vascular resistance was not influenced by NKY.

\section{Effects of NKY-722 on the Effects of Endothelin-1} (ET)

Effects on the Hemodynamic Parameters (Table 1): Saline (NKY in low or high doses) was first IV injected in a bolus, and IV injections of ET $(5 \mathrm{mg} / \mathrm{kg})$ followed $10 \mathrm{~min}$ later. ET followed by saline infusions transiently decreased blood pressure immediately after the injection for less than $1 \mathrm{~min}$. This was followed by an increase in blood pressure with the peak elevations at 3-5 min. Hemodynamic parameters were measured at the peak pressor response. ET changed blood pressure by $+23 \pm 2$ $\mathrm{mmHg}$, and heart rate by $-12 \pm 8$ beats $/ \mathrm{min}$ at $3-5$ min. CO and CI were greatly decreased by ET, and total peripheral resistance index increased markedly. Pretreatments with NKY significantly suppressed the pressor responses to ET. CO and CI after ET tended to increase with the pretreatment. Consequently, total peripheral resistance index was markedly decreased.

Effects on the Regional Blood Flow (Table 2): ET decreased the flow in the liver, spleen, kidneys, adrenals, BAT, intestine, colon and skeletal muscle. It did not significantly influence the flow in the heart and skin, and rather increased it in the brain and lungs.

Pretreatment with NKY prevented the decrease of flow caused by ET in the kidneys, adrenals, BAT, intestine, colon and skeletal muscle, although it was ineffective in the brain, lungs, and skin. Pretreatments with NKY decreased, on the other hand, the flow in the liver and spleen.

Effects of NKY on the Regional Vascular Resistance (Fig. 1-a, b): ET increased the resistance in the kidneys, adrenals, BAT, colon and skeletal muscle. It did not significantly influence the flow in the heart, lungs, liver, spleen, intestine, and skin, and rather tended to decrease resistance in the brain and lungs.

Pretreatment with NKY prevented the increase of vascular resistance caused by ET in the kidneys, adrenals, BAT, intestine, colon and skeletal muscle, but it was ineffective in the brain, lungs, and skin. Pretreatment with NKY rather increased the resistance in the liver.

\section{Discussion}

Calcium channel blockers are now widely used as antihypertensive agents because they show minimum adverse effects and do not decrease the regional blood flow in major organs such as the brain, the kidneys and the heart $(7,8)$. Among them, dihydropyridine calcium channel blockers are more vasoselective than diltiazem and verapamil, and do not suppress cardiac functions at doses causing vasodepression. Therefore, the former is preferred for the purpose of antihypertensive medication.

In the present study, it was also found that NKY

Table 2. Effects of the Treatments on the Regional Blood Flow ( $\mathrm{ml} / \mathrm{min}$ per g-tissue weight) in 6 Groups of Rats

\begin{tabular}{|c|c|c|c|c|c|c|}
\hline Rat Group & Brain & Heart & Lungs & Liver & Spleen & Kidneys \\
\hline Control & $0.33 \pm 0.042^{\dagger \dagger}$ & $2.88 \pm 0.564$ & $0.21 \pm 0.032$ & $0.23 \pm 0.059^{\dagger}$ & $1.17 \pm 0.151^{\dagger \dagger}$ & $2.57 \pm 0.180^{\dagger \dagger}$ \\
\hline NKY-L & $0.51 \pm 0.039$ & $3.39 \pm 0.487$ & $0.64 \pm 0.242$ & $0.13 \pm 0.017^{* *}$ & $0.56 \pm 0.062^{* *}$ & $1.76 \pm 0.170^{* * \dagger \dagger}$ \\
\hline NKY-H & $0.75 \pm 0.085^{*}$ & $2.70 \pm 0.254$ & $0.69 \pm 0.147$ & $0.10 \pm 0.007^{* *}$ & $0.24 \pm 0.040^{\text {** } \dagger}$ & $1.88 \pm 0.159^{* \dagger \dagger}$ \\
\hline ET & $0.60 \pm 0.066^{* *}$ & $2.85 \pm 0.293$ & $0.90 \pm 0.151$ & $0.14 \pm 0.012^{*}$ & $0.61 \pm 0.140^{* *}$ & $0.97 \pm 0.255^{* *}$ \\
\hline NKY-L/ET & $0.46 \pm 0.031$ & $3.42 \pm 0.595$ & $1.01 \pm 0.470^{*}$ & $0.13 \pm 0.017^{\text {** }}$ & $0.30 \pm 0.040^{*{ }^{\dagger} \dagger}$ & $1.33 \pm 0.095^{* *}$ \\
\hline NKY-H/ET & $0.44 \pm 0.040$ & $3.77 \pm 0.981$ & $0.83 \pm 0.233$ & $0.07 \pm 0.008^{* *}$ & $0.18 \pm 0.054^{* * \dagger}$ & $1.05 \pm 0.100^{* *}$ \\
\hline$F$ ratio & 6.15 & 0.56 & 1.26 & 4.62 & 11.75 & 10.27 \\
\hline$p<$ & 0.0003 & 0.7327 & 0.3044 & 0.0023 & 0.0001 & 0.0001 \\
\hline Rat Group & Adrenals & $\mathrm{BAT}$ & Intestine & Colon & Muscle & Skin \\
\hline Control & $6.60 \pm 1.759^{\dagger}$ & $0.24 \pm 0.073$ & $0.76 \pm 0.103$ & $0.55 \pm 0.063^{\dagger}$ & $0.15 \pm 0.031^{\dagger \dagger}$ & $0.05 \pm 0.007$ \\
\hline NKY-L & $7.07 \pm 0.909^{\dagger \dagger}$ & $0.50 \pm 0.074^{\dagger \dagger}$ & $1.08 \pm 0.082^{* \dagger \dagger}$ & $0.71 \pm 0.061^{\dagger+*}$ & $0.06 \pm 0.008^{* *}$ & $0.06 \pm 0.010$ \\
\hline NKY-H & $2.42 \pm 0.735^{* *}$ & $0.68 \pm 0.128^{* *^{\dagger \dagger}}$ & $1.33 \pm 0.111^{* * \dagger}$ & $0.82 \pm 0.057^{\text {**† }}$ & $0.08 \pm 0.010^{\text {** } \dagger}$ & $0.10 \pm 0.016^{* * \dagger \dagger}$ \\
\hline ET & $2.68 \pm 0.724^{*}$ & $0.09 \pm 0.033$ & $0.58 \pm 0.077$ & $0.33 \pm 0.033^{*}$ & $0.03 \pm 0.009^{* *}$ & $0.05 \pm 0.012$ \\
\hline NKY-L/ET & $3.00 \pm 0.512^{*}$ & $0.44 \pm 0.032^{\dagger \dagger}$ & $0.70 \pm 0.035$ & $0.43 \pm 0.026$ & $0.06 \pm 0.006^{* *}$ & $0.05 \pm 0.006$ \\
\hline NKY-H/ET & $7.33 \pm 0.628^{\dagger \dagger}$ & $0.44 \pm 0.073^{\dagger \dagger}$ & $0.74 \pm 0.104$ & $0.46 \pm 0.079$ & $0.06 \pm 0.012^{* *}$ & $0.05 \pm 0.009$ \\
\hline$F$ ratio & 5.80 & 9.28 & 10.53 & 12.56 & 8.67 & 3.04 \\
\hline$p<$ & 0.0005 & 0.0001 & 0.0001 & 0.0001 & 0.0001 & 0.0221 \\
\hline
\end{tabular}

Abbreviations: BAT, brown adipose tissue; muscle, skeletal muscle. Abbreviations of group name are arranged as in Table 1. $\left({ }^{*} p<0.05,{ }^{* *} p<0.01 v s\right.$. control group, ${ }^{\dagger} p<0.05,{ }^{\dagger \dagger} p<0.01 v s$. ET group with multiple range test). 

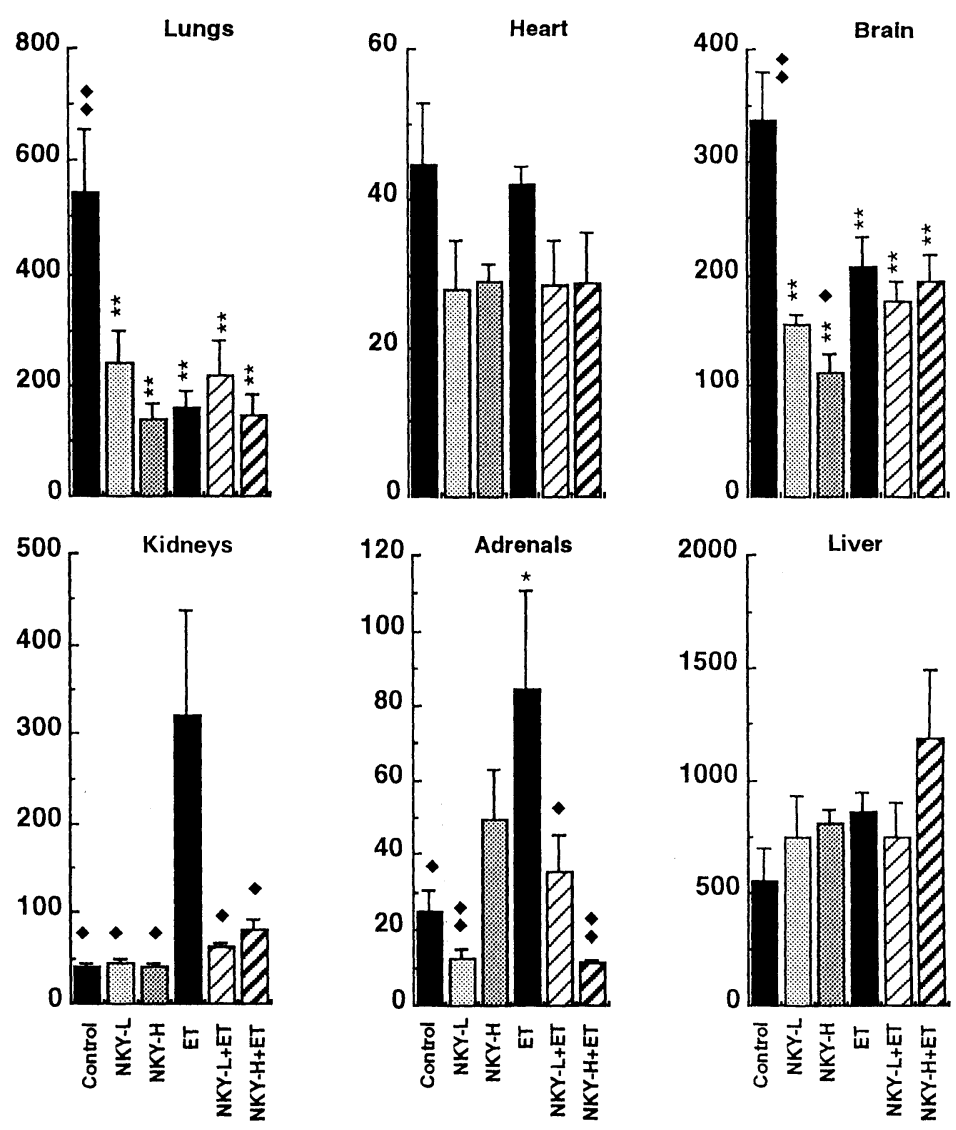

Fig. 1-a. Effcts of the treatments on the regional vascular resistance ( $\mathrm{mm} \mathrm{Hg} \cdot \mathrm{min} / \mathrm{ml} \cdot \mathrm{g}$ ) in 6 groups of anesthetized rats. Abbreviations: NKY-L, low dose (0.2 mg/kg); NKY-H, high dose (2 mg/kg); ET, endothelin-1 (5 mg/kg); NKY-L + ET, low dose NKY and ET; NKY-H/ET, high dose NKY and ET. $\left({ }^{*} \mathrm{p}<0.05,{ }^{*} \mathrm{p}<0.01\right.$ vs. control group, ${ }^{*}<0.05,{ }^{\star} \mathrm{p}<0.01$ vs. ET group with a multiple range test).

increased $\mathrm{CO}$, and did not decrease the flow in the major organs. Rather, NKY significantly increased the blood flow in the brain. Calcium channel blockers are usually known to increase regional blood flow in many organs and tissues (9). However depending on the dose, they may not influence the regional blood flow because they may also dilate the capacitance vessels to decrease the venous return and CO. The dose of NKY used in the present study might have been relatively large enough to dilate not only the resistance vessels but also the capacitance vessels. Therefore, the flow in the kidneys, spleen and skeletal muscle was rather decreased.

The most characteristic feature of the regional vascular effects of NKY was a marked increase in the blood flow in BAT. BAT is thought to play a role in non-shivering and diet-induced thermogenesis (10). In addition, a functional deficit in BAT is considered to be responsible for the genesis of obesity. A typical $\beta$-agonist ( $\beta_{3}$-adrenergic agonist) has been known to reduce weight by causing thermogenesis via activation of BAT (11). Thermogenesis caused by a $\beta_{3}$-agonist is accompanied by increased blood flow in BAT (12). The increase in regional blood flow in BAT is thought to be an indicator of tissue activities such as, thermogenesis in BAT. BAT is richly innervated with sympathetic nerve fibers, which are activated by, among other possibilities, ventromedial hypothalamic nuclei in the brain (13). There are two possibilities for the increase in regional blood flow: one is the direct effect of NKY on the vessels in BAT to dilate, and the other is the indirect effect through sympathetic activation. The marked increase in BAT blood flow by NKY may be a response via sympathetic activation innervating BAT. Because NKY is highly hydrophilic, and scarcely passes the blood-brain barrier, it is possible that this sympathetic activation is caused by the baroreceptor reflex. We previously found that a calcium channel blocker initially caused sympathetic activation for less than $2 \mathrm{~min}$ due to the baroreceptor reflex, and the activity rather decreased later (14). Intracerebroventricular injections of diltiazem decreased peripheral sympathetic discharge in anesthetized rats. In our present study, reflex tachycardia was not observed during the vasodepression. Sympathetic activation by baroreceptor reflex may be minimal with intravenous injections of NKY, possibly because of the urethane-anesthesia. The major cause of increases in BAT blood flow in the present study might not be sympathetic activation. 

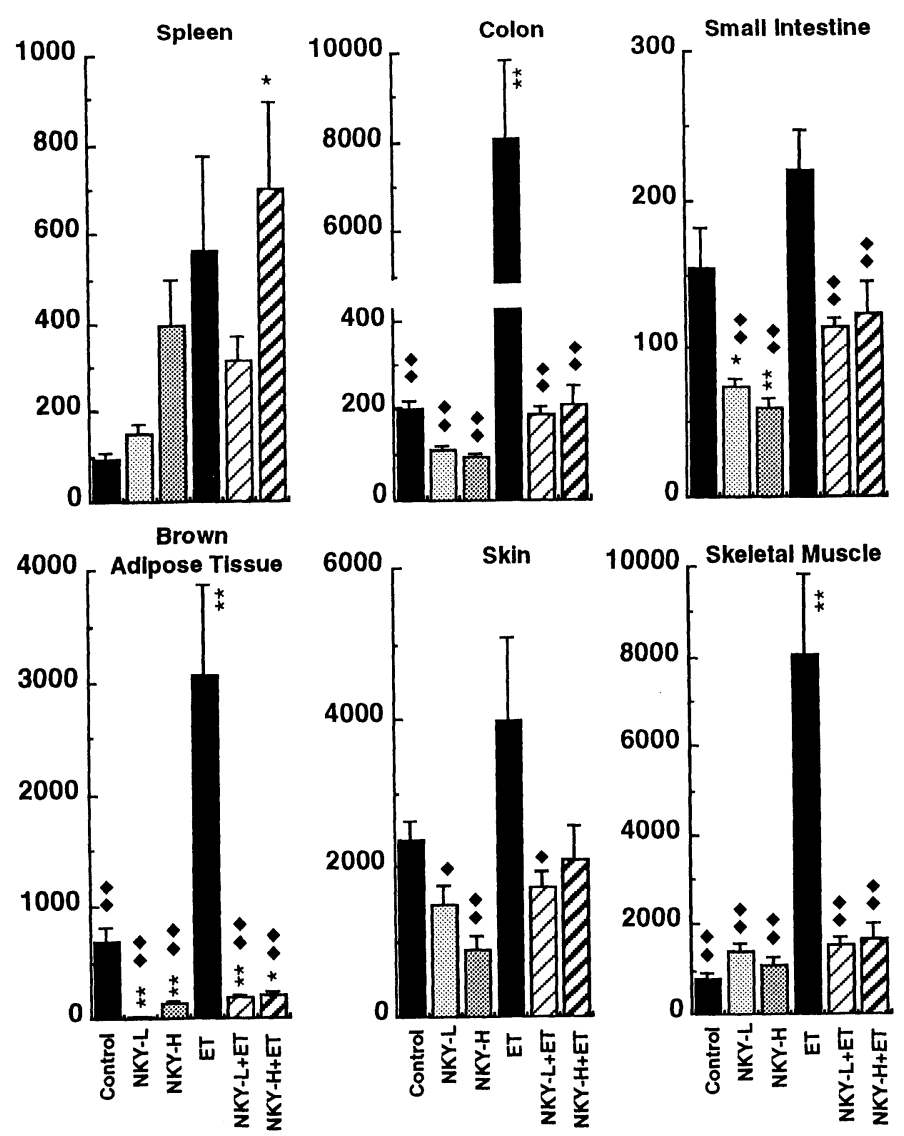

Fig. 1-b. Effects of the treatments on the regional vascular resistance $(\mathrm{mm} \mathrm{Hg} \cdot \mathrm{min} / \mathrm{ml} \cdot \mathrm{g})$ in 6 groups of anesthetized rets. Abbreviations: NKY $-L$, low dose $(0.2 \mathrm{mg} / \mathrm{kg}) ; N K Y-H$, high dose $(2 \mathrm{mg} / \mathrm{kg}) ; \mathrm{ET}$, endothelin-1 $(5 \mathrm{mg} / \mathrm{kg}) ; \mathrm{NKY}-\mathrm{L}+\mathrm{ET}$, low dose NKY and ET; NKY-H/ET, high dose NKY and ET. $\left({ }^{*} \mathrm{p}<0.05,{ }^{* *} \mathrm{p}<0.01\right.$ vs. control group, ${ }^{*} \mathrm{p}<0.05,{ }^{*} \mathrm{p}<0.01$ vs. ET group with a multiple range test).

But, because NKY is a potent vasodilator, it may be natural to think that NKY directly dilated the vasculature particularly in BAT. Increased blood flow in BAT may activate the metabolism to cause thermogenesis in the tissue. Whether or not NKY elicits reduction of weight in obese patients and animals is yet to be investigated.

ET is a potent vasoconstrictor peptide derived from vascular endothelial cells. It is thought that ET is released when endothelial cells are stimulated mechanically (15) or chemically (16). Atherogenic processes may also promote release of ET by various kinds of substances released from activated platelets and leukocytes (17). In fact, plasma concentrations of immunoreactive ET are increased in hypertensive patients with hypertensive complications (18). Suppression of the effect of ET in such patients as those with hypertension and atherosclerosis may lead to prevention of their target organ damage. Yanagisawa et al. (3) first showed that a calcium channel blocker, nicardipine, attenuated the vasoconstrictive responses to ET in rats, although the underlying mechanism has not yet been fully elucidated. Calcium channel blockers do not directly affect the ET receptors, but indirectly suppress ET-receptor-mediated signal-transduction resulting in abolition of the sustained increase in intracellular calcium concentrations caused by ET (19). Eventually, calcium channel blockers antagonize vascular effects of ET. As was shown in the present study, NKY constricted arteries in many organs and tissues except the brain, heart and lungs at the dose used. NKY also significantly prevented ET-induced vasoconstriction in various organs and tissues in rats. It was potent in the kidneys, adrenals, BAT, intestine, colon and skeletal muscle. Since the total, absolute amount of blood flow into these organs and tissues may be more than $40 \%$ of $\mathrm{CO}$, the vascular effects of ET on these organs may be the determinant of the hemodynamic influences of ET. Because pretreatments with NKY abolished the vascular effects of ET in these organs and tissues, this calcium channel blocker was found to be potent enough in antagonizing the vascular effects of ET.

These results indicate that administration of NKY should be useful for maintenance of the regional blood flow in patients with atheromatous lesions and/or hypertension, and that it may have an additional benefit for obese hypertensives because it increases blood flow in BAT and may augment thermogenesis. 


\section{Acknowledgment}

We thank Miss Masako Konishi for typing the manuscript. This investigation was partly supported by a Grantin-Aid for Scientific Research from the Ministry of Education, Science and Culture of Japan (No. 02304033).

\section{References}

1. Osumi S, Morishita S, Wada K, et al: Antihypertensive effect of NKY-722, a new water-soluble 1,4dihydropyridine derivative, on conscious spontaneously hypertensive rats. Tohoku J Exp Med 1988; 155: 205-206.

2. Inagawa J, Satoh K, Taira N: Coronary vasodilator and cardiac effects of NKY-722, a novel hydrophilic 1,4-dihydropyridine derivative, in the blood-perfused dog heart. Cardiovasc Drugs Ther 1989; 3: 81-89.

3. Yanagisawa $M$, Kurihara $\mathrm{H}$, Kimura S, et al: A novel potent vasoconstrictor peptide produced by vascular endothelial cells, Nature 1988; 332: 411-415.

4. Seino M, Abe K, Nushiro N, et al: Interaction of endothelin and $\mathrm{Ca}^{+}$entry blockers on renal circulation in anesthetized rabbits. Clin Exp Hypertens 1990; A12: 205-213.

5. Minkes RK, Kadwitz PJ: Influence of endothelin on systemic arterial pressure and regional blood flow in the cat. Eur J Pharmacol 1989; 163: 163-166.

6. Clozel M, Clozel J-P: Effects of endothelin on regional blood flows in squirrel monkeys. $J$ Pharmacol Exp Ther 1989; 250: 1125-1131.

7. Oizumi T, Nishino H, Miyake S, et al: Hemodynamic changes following long-term administration of CS905 , a novel dihydropyridine calcium channel blocker, in conscious SHR. Jpn J Pharmacol 1990; 54: $1-6$.

8. Nagaoka A, Shibota M, Hamajo K: Effects of a new dihydropyridine derivative, $\mathrm{CV}-4093-2 \mathrm{HCl}$, on renal hemodynamics in spontaneously hypertensive rats. Jpn J Pharmacol 1989; 51: 25-35.

9. Hof RP, Hof A, Takiguchi Y: Attenuation of endothelin-induced regional vasoconstriction by isra- pidine: a nonspecific antivasoconstrictor effect. $J$ Cardiovasc Pharmacol 1990; 15 (suppl.1): S48-S54

10. Rothwell N, Stock MJ: A role for brown adipose tissue in diet-induced thermogenesis. Nature 1979; 281: 31-35.

11. Arch JRS, Ainsworth AT, Cawthorne MA, et al: Atypical $\beta$-adrenoceptors on brown adipocites as a target for anti-obesity drugs. Nature 1984; 309: 163-165.

12. Takahashi H, Yoshida T, Nishimura M. Nakanishi T, Kondo M, Yoshimura M: Beta-3 adrenergic agonist, BRL-26830A, and alpha/ beta blocker, arotinolol, markedly increase regional blood flow in the brown adipose tissue in anesthetized rats. Jpn Circ J 1992; 56: $936-942$.

13. Iwai M, Hell NS, Shimazu T: Effect of ventromedial hypothalamic stimulation on blood flow of brown adipose tissue in rats. Pflugers Arch 1987; 410: 44-52.

14. Iyoda I, Takahashi $\mathrm{H}$, Takeda $\mathrm{K}$, et al: Centrally-induced vasodepressor responses to diltiazem, a calcium channel blocker, in rats. J Hypertens 1985; 3: 639-644

15. Yoshizumi $\mathrm{M}$, Kurihara $\mathrm{H}$, Sugiyama $\mathrm{T}$, et al: Hemodynamic shear stress stimulates endothelin production by cultured endothelial cells. Biochem Biophys Res Commun 1989; 161: 859-864.

16. Kurihara H, Yoshizumi M, Sugiyama $\mathrm{T}$, et al: Transforming growth fator-b stimulates the expression of endothelin mRNA by vascular endothelial cells. Biochem Biophys Res Commun 1989; 159: 1435-1440.

17. Rau L: Hypertension, endothelium, and cardiovascular risk factors. Am J Med 1991; 90 (suppl 2A): $13 \mathrm{~s}-18 \mathrm{~s}$.

18. Saito N, Nakao K., Mukoyama M., Imura H: Increased plasma endothelin level in patients with essential hypertension. N Engl J Med 1990; 322: 205

19. Hirata Y, Yoshimi H, Takata S, et al: Cellular mechanism of action by a novel vasoconstrictor endothelin in cultured rat vascular smooth muscle cells. Biochem Biophys Res Commun 1988; 154: 868-875. 